\title{
An Eight Year Retrospective Study on the Prevalence of Hernias in Large Animals at the Veterinary Teaching Hospital Ahmadu Bello University, Zaria
}

\author{
Fadason Samuel Tanko ${ }^{1}$, Ameh Veronica Odinya ${ }^{1}$, Andrew Augustine', \\ Remi-Adewunmi Bola Dupe ${ }^{1}$, Usman Bala ${ }^{2}$, Kwanashie Garba ${ }^{2}$, Okaiyeto Solomon Olu ${ }^{2}$ \\ ${ }^{1}$ Department of Veterinary Surgery and Radiology, Ahmadu Bello University, Zaria, Kaduna State, Nigeria \\ ${ }^{2}$ Veterinary Teaching Hospital, Ahmadu Bello University, Zaria, Kaduna State, Nigeria
}

Email address:

sokaiyeto@ymail.com (O. S. Olu)

To cite this article:

Fadason Samuel Tanko, Ameh Veronica Odinya, Andrew Augustine, Remi-Adewunmi Bola Dupe, Usman Bala, Kwanashie Garba, Okaiyeto Solomon Olu. An Eight Year Retrospective Study on the Prevalence of Hernias in Large Animals at the Veterinary Teaching Hospital Ahmadu Bello University, Zaria. Animal and Veterinary Sciences. Vol. 3, No. 4, 2015, pp. 125-127. doi: 10.11648/j.avs.20150304.16

\begin{abstract}
Records of animals presented to Large Animal Clinic of Veterinary Teaching Hospital Ahmadu Bello University Zaria (VTHABU) from 2002-2009 were studied and analyzed to evaluate the occurrence and management of hernias presented to the clinic. A total of one thousand five hundred and ninety- five $(1,595)$ cases were presented during the period under review. Three hundred and ten $(19.4 \%)$ of these cases were treated surgically while $1,285(80.6 \%)$ were medical cases. One hundred and ninety seven $(63.5 \%)$ of the surgeries were in females, and $113(36.5 \%)$ in males. Out of these, a total of $16(1 \%)$ cases of hernia were presented. Thirteen $(81.25 \%)$ were ventral abdominal hernias and $3(18.75 \%)$ scrotal hernias. Eight $(50 \%)$ of the hernia cases were in females and $8(50 \%)$ in males. More hernia cases $(68.75 \%)$ were recorded in ovine, while $8.75 \%$ cases were recorded in bovine and $12.5 \%$ in caprine. No case of hernia was recorded in equine and porcine. During this period, diagnoses of hernia were based on physical examination and all the cases were managed surgically by herniorrhaphy.
\end{abstract}

Keywords: Hernia, Herniorrhaphy, Bovine, Goat, Sheep, Trauma

\section{Introduction}

Hernia is the protrusion of a part of an organ or structure through the tissue that normally contains it [1] (Lippincott and Wilkins 2006). Hernias are also known as ruptures [2] (Edward, 2005) and they could have many deleterious effects such as lowering the productivity and reproduction of the affected animals [3] (Abdin-Bey and Ramadan 2001). A typical hernia always consist of the "hernia ring" or an opening in the muscle which may have been brought about as a result of an accident, or may have been present at birth; a swelling appearing below the skin "hernia sac", and the "hernia content" [4] [2] (Gyang, 1988; Edward, 2005). The hernia sac is usually made up of the skin, muscle fibers or fibrinous connective tissue, and sometimes the peritoneum, while the hernia content may be a loop of intestine, omentum, peritoneal fluid, urinary bladder, stomach, or the uterus [4] (Gyang, 1988). Hernias may be acquired or congenital, and when congenital, it is inherited as a dominant character [5]
(Weaver et al., 2005).

Hernias can be caused by so many factors like horn-goring, falls, kicks, automobile accidents and increase in intra abdominal pressure [6] (Blood et al., 1997). Factors such as wound dehiscence, obesity, weight of the rumen, continuous standing on slopping rumps, naval infections and pregnancy generally predispose animals to hernia [7] (Blood et al., 1997; [2] Edward, 2005).

A hernia can be described as being reducible, when its contents can be completely and easily returned into the abdominal cavity, or irreducible, when its content cannot be completely returned into the abdominal cavity, due to adhesion, strangulation or incarceration of the herniated tissue [4] (Gyang, 1988).

There are various types of hernias, a few of which include; ventral abdominal, lateral abdominal, scrotal and inguinal, umbilical, diaphragmatic, perineal, incisional, haital, intracranial, and mesenteric hernias. But of all these, umbilical, ventral abdominal, diaphragmatic and scrotal hernias have been more frequently encountered in animals [7] 
(Hassan and Hassan, 2003). Abdominal, inguinal and perineal hernias can entrap a fetus or fetuses in their hernia sac leading to dystocia [8] (Radhakrishnan et al., 1993; [9] Sobiraj, 1994).

Despite all these effects, reports on hernias in large animals in this region are rare. There is therefore the need for more attention to be given to the study of hernia particularly in large animals. The aim of this study was to determine the prevalence of hernias and the types presented to the VTHABU Zaria-Nigeria and how they were diagnosed and managed.

\section{Materials and Method}

This study was carried out using the clinic records in patient files of all animals that were presented to the Large Animal Clinic of the Veterinary Teaching Hospital Ahmadu Bello University, Zaria, Nigeria, from January 2002 to December 2009. Zaria is a town in Kaduna State situated in the Northern Nigeria with the geographical coordinates of $11^{\mathrm{O}} 4^{\prime}$ 'North and $7^{\circ} 42^{\prime}$ East [10] [11] (Anon, 2005; Anon, 2010). The files were carefully examined and records were isolated and evaluated. Medical and surgical cases were separated and the surgical case was further analyzed. The data were rearranged and grouped based on species, sex and surgical procedure. The cases were analyzed to determine type and prevalence of hernia as presented to the Large Animal Clinic using simple descriptive statistics.

\section{Results}

A total of 1,595 cases were presented to the Large Animal Clinic of the Veterinary Teaching Hospital, Ahmadu Bello University, Zaria, from January 2002 to December, 2009. Out of these, $310(19.4 \%)$ were surgically managed while 1,285 $(80.6 \%)$ were medical cases. One hundred and thirteen (36.5\%) surgeries were performed in males and 197 (63.5\%) surgeries were done in females. The surgical procedures recorded were as follows: hoof trimming, atresia ani correction, caesarean section, castration, dehorning, rumenotomy, traumatic injuries treatment, abscess lancing, relieve of mango choke, prolapse reduction, fracture reduction, manual traction of fetuses in dams with dystocia and herniorrhaphy.

A total of 16 hernia cases $(5.16 \%)$ were handled surgically, giving a prevalence of $0.01 \%$. No case of hernia was recorded in Equine and Porcine species. The ovine species had the highest percentage of occurrence $(68.75 \%)$, followed by Caprine (18.75\%), and Bovine species (12.5\%) (Table 1). Out of these 16 hernia cases, $8(50 \%)$ were in females, while the remaining $8(50 \%)$ were in males. Three $(18.75 \%)$ of the hernia cases were scrotal hernia (Plate 1), and 13 (81.25\%) were ventral abdominal hernia (Plate 2). All the hernia cases were reducible hernias and diagnosis was based on clinical examination. All the hernia cases were successfully managed by herniorrhaphy.
Table 1. Species distribution of hernia cases presented to large animal clinic ABUTH Zaria-Nigeria from 2002 to 2009.

\begin{tabular}{llll}
\hline species & Number of cases & percentage & mean \\
\hline Bovine & 2 & 12.5 & $0.3 \pm 0.16$ \\
Caprine & 3 & 18.75 & $0.4 \pm 0.26$ \\
Ovine & 11 & 68.75 & $1.4 \pm 0.32^{*}$ \\
Equine & 0 & 0 & 0 \\
Porcine & 0 & 0 & 0 \\
Total & 16 & 0 & 0 \\
\hline
\end{tabular}

* Significant difference $(\mathrm{p}<0.05)$

\section{Discussion}

The results show that $19.4 \%(310 / 1595)$ of all cases presented to the Large Animal Clinic of VTHABU were managed surgically. This underscores the importance of surgically related problems in veterinary large animal practice. More surgeries were done in female animals than males in the years under review, which may be due to the fact that farmers keep more females than males for production purposes. Obstetrical problems which are commonly managed surgically may have contributed to this finding.

Equal numbers of hernia cases were recorded in males and females. This is in variance with the finding of [3] AbdinBey and Ramadan (2001), who reported that more male goats had hernia than female goats in Saudi Arabia.

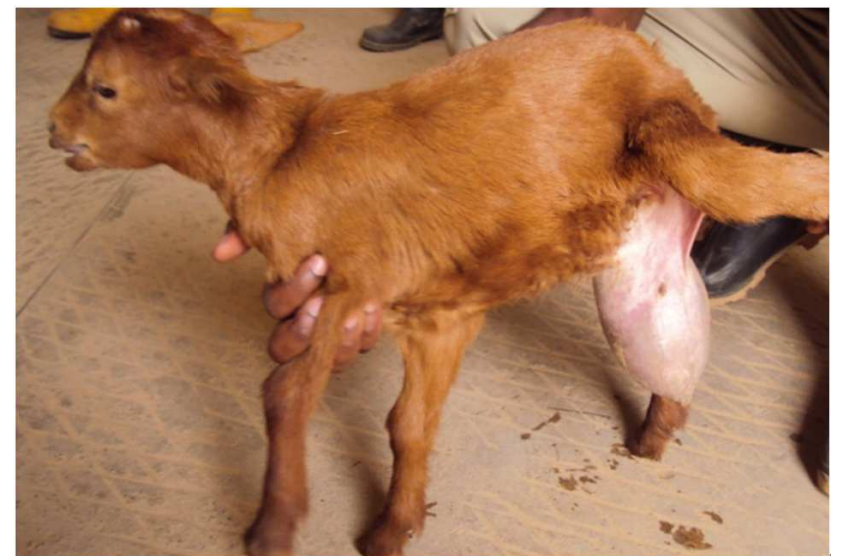

Plate 1. A Red Sokoto kid presented to the ABUVTH Zaria-Nigeria with a large scrotal hernia during the period.

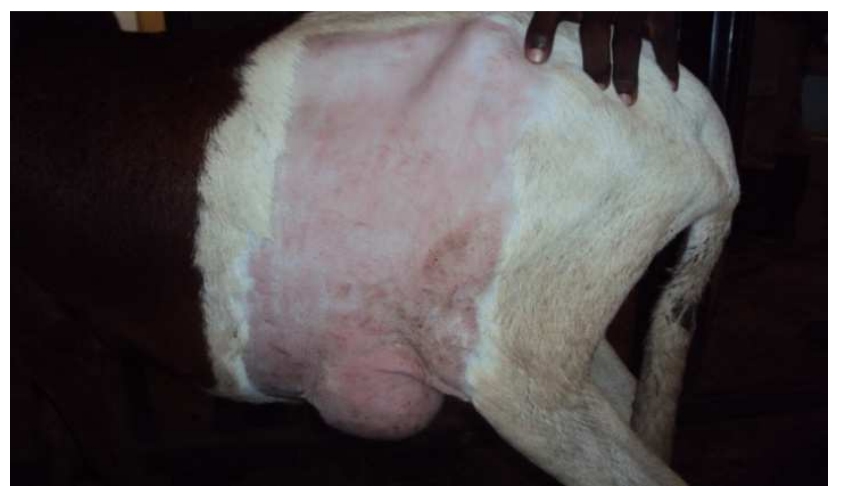

Plate 2. Left ventral abdominal hernia in an ewe presented to the ABUVTH Zaria-Nigeria. 
It was observed in this study that the prevalence of hernias in the Large Animal Clinic, VTHABU Zaria is low (0.01\%). Ovine species had higher hernia cases as compared to other species. This study also revealed that sheep were more prone to hernias due to trauma than goats, probably due to their timid behavior. These findings did not agree with the report of [12] Fahd and Ahmed (2007) who observed a higher incidence of hernia in goats than sheep. This was probably attributed to the fact that goats have relatively thinner abdominal wall than sheep as suggested by [13] Smith and Sherman (1994). Since the major cause of hernia in this study was attributed to trauma, it suggests that the extensive management systems of rearing these animals are faulty, as they could easily be exposed to trauma.

Physical examination was used to diagnose all cases of hernia presented. This suggests that where diagnostics tools are not available physical examination can be relied on for proper diagnosis of hernia. However, it is also important for such diagnosis to be confirmed by radiography, ultrasonography and computed tomography.

\section{Conclusion}

Based on this study, the prevalence of hernia is low in Zaria and Sheep were more prone to hernias due to trauma from other farm animals. Farm animals should be raised under intensive system of management to reduce exposure to traumatic hernia thereby lowering economic losses due to hernias to the livestock industry in Nigeria. Modern techniques for hernia diagnoses and corrections should also be employed.

\section{References}

[1] Lippincott, W. and Wilkins. Stedman's medical dictionary, $28^{\text {th }}$ edition. Wolter Kluwer Health Company, Baltimore, Maryland, USA. pp $879-881,2006$.
[2] Edward, B. Blacks Veterinary Dictionary, twenty-first edition. A and C Black, London, pp 332-334, 2005.

[3] Abdin-Bey, M. R., and Ramadan, R.O. (2001). Retrospective study of hernias in goats. Scientific Journal of King Faisal University, Saudi Arabia.2001; 2:77-86.

[4] Gyang, E. O. Thoracic and Abdominal wall, Herniorraphy in Large Animals. In: Introduction to Large Animal Surgery. Agitab publishers Ltd, Nigeria. pp 256-266, 1988.

[5] Weaver, A. D., Steiner, A. and St. Jean, G. Abdominal surgery. In: Bovine Surgery and Lameness. $2^{\text {nd }}$ edition. Blackwell Scientific Publications. Garsington Road Oxford, U.K. pp122127, 2005.

[6] Blood, D. C., Radostits, O. M. and Gay, C. C. (1997). Diseases of respiratory system. In: Textbook of Diseases of Cattle, Sheep, Pigs, Goats and Horses. W. B. Saunders Company Ltd, Philadelphia. pp 421-422, 1997.

[7] Hassan, A. Z. and Hassan, F. B. Soft Tissue Surgery. In: Introduction to Veterinary Practice. Ahmadu Bello University Press Limited, Zaria-Nigeria. 2003; Pp 299-300.

[8] Radhakrishnan, C., Balasubraman, S. and Thilagar, S. Repair of ventral metrocele (gravid) in a goat. Veterinary Records. 1993; 132: 92-93.

[9] Sorbiraj, A. Birth difficulties in sheep and goats, evaluation of patients out come from seven lambing periods in an obstetrical clinic. DTW, Dtsch Tierarztl wochenschr. 1994; 101:471-476.

[10] Anonymous. Zaria map-Satellite images of Zaria. http://www.maplanda.com/ nigeria/kaduna/sabon-gari/zaria 2005 (Accessed: 29/11/10, time: $2.30 \mathrm{pm}$ ).

[11] Anonymous. Zaria. http://wikipedia.org/wiki/zaria2010 (Accessed: 24/11/10, time: $2.30 \mathrm{pm}$ ).

[12] Fahd, A.A and Ahmed, F.A (2007). Surgical treatment for different forms of hernias in sheep and goats. Journal of Veterinary Sciences, 2007; 8(2): 185-191.

[13] Smith, M.C. and Sherman, D.M. (1994). Goat Medicine. Lea and Febiger, Philadelphia, United States of America, pp. 56-57, 1994. 